\title{
Differential Diagnosis of Aphthous Lesions in Children
}

Ganeva $\mathrm{M}^{1 *}$, Stefanov St ${ }^{1}$, Lisichki K²

'Department of Pediatric Rheumatology, University Children's Hospital, Medical University Sofia, Bulgaria ${ }^{2}$ Acibadem City Clinic Tokuda Hospital, Pediatric Department, Bulgaria

*Corresponding author: Margarita Ganeva, Department of Pediatric Rheumatology, University Children's Hospital, Medical University Sofia, Bulgaria

\section{Case Study}

The term aphthae is derived from the Greek word aphthi, which means "to set on fire" or "to inflame," and is thought to have been first used by the philosopher Hippocrates to describe the pain associated with a common disorder of the mouth during his time (likely, aphthous stomatitis). Aphthous ulcers are reported as the most common oral mucosal lesions in the general population [1] A large US study comprising of 10,030 individuals aged between 2 and
17 years, described oral lesions in 914 (9.11\%) of them [2] The most commonly affected sites were the lips in $30.7 \%$ of the affected children, followed by the dorsum of the tongue (14.7\%) and the buccal mucosa (13.6\%). The most prevalent lesions were lip/cheek bite (1.89\%), followed by aphthous stomatitis (1.64\%), recurrent herpes labialis (1.42\%) and geographic tongue (1.05\%).

Aphtha is defined as a superficial lesion of the oral

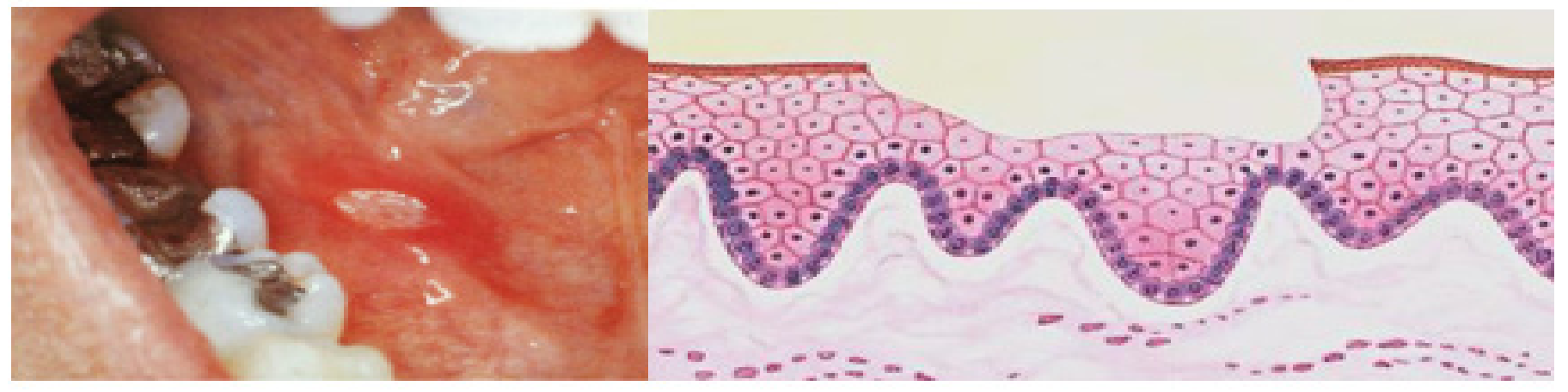

Figure 1
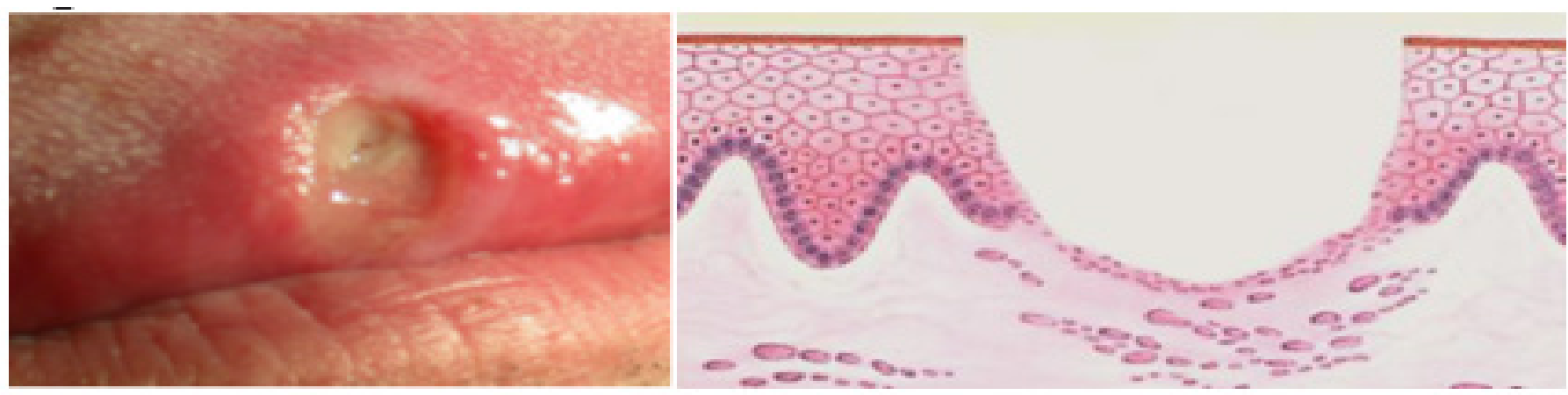

Figure 2 
mucosa with a round or polygonal shape, surrounded by a bright red halo. Its bottom is covered with a withish fibrinous deposit. Aphthae do not penetrate deep into the basement membrane and as such they heal without leaving a scar. (Figure 1). In the case of ulceration the defect crosses the basal layer of the epithelium and enters the underlying lamina propria. After healing of the ulcer a scar remains. (Figure 2).
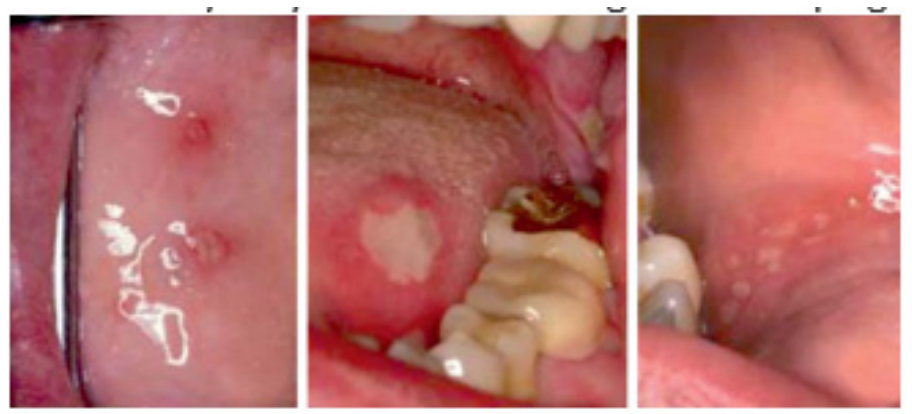

Figure 3

There are Three Main Types of Aphthous Lesions:

\section{Aphthous Ulcer Minor (Mikulicz Ulcer)}

The most common subtypes (75\% of cases); involve movable and nonkeratinized oral mucosa, principally the mucosa of the cheek, lip, floor of mouth, ventral and lateral surface of tongue; represent round or oval lesions, with gray-white pseudomembranes and eryhtematous halo; usually less than $1 \mathrm{~cm}$ in diameter; persist for $1-2$ weeks and heal without scar. Scarring occurs in around $8 \%$ of cases.

\section{Aphthous Ulcer Major (Sutton Ulcer, Periadenitis Mucosa Necrotica Recurrens)}

Lest commonly observed (10-15\% of cases); usually involves the soft palate, tonsils, labial and buccal mucosa, but also the keratinized epithelium - tongue and hard palate; usually greater than $1 \mathrm{~cm}$ in diameter; can last for 10 days to 6 weeks; because of the greater depth of involvement, they are more painful, slower to heal (taking up to 6 weeks), and usually leave a scar; large ulcerations can also be associated with problems such as pharyngeal involvement, dysphagia, and dyspnea or fistulae involving the pharynx, larynx, trachea or esophagus.

\section{Herpetiform Aphthous Ulcers}

Are very small (1-2mm) grouped lesions. They account for around $5 \%$ of recurrent oral aphthous ulcers, are extremely painful and persist for 7-10 days. As many as a 100 ulcers can be present; they may coalesce into larger erosive plagues.
As being a commoncondition it is important to know the differential diagnosis of aphthous lesions, as listed in (Table 1).

The development of aphthous lesions goes through different stages:

Prodromal Stage

Usually lasting 24 hours with itching and burning sensation.

\section{Preulcerative Stage}

Taking up to 3 days. In this stage development of a localized painful papular swelling because of keratinocyte vacuolization surrounded by a reactive erythemathous halo representing localized vasculitis with a dense mononuclear cell infiltrate are observed.

\section{Ulcerative Stage}

Usually lasting 1-16 days and only in rare cases when involving large ulcerations, up to 6 weeks; the already formed painful papule ulcerates and a fibrous membrane covers the ulcer which is infiltrated mainly by neutrophils, lymphocytes and plasma cells.

\section{Healing Stage}

With epithelial regeneration

The most common idiopathic intraoral ulcerative disease is Recurrent Aphthous Stomatitis (RAS). It affects 10$10 \%$ of the overall population. In children it represents $40 \%$ of the relapsing ulcers in children [3]. US study comprises 39,206 children aged 5-17 yr who were examined by 14 dentists and found out a prevalence of RAS of $1.23 \%$ in children [4]. RAS can have different time course. The simple chronic recurrent oral aphthous ulcers present with a limited number of small, quickly healing, minimally painful ulcers limited to the oral mucosa and recurring with 3-6 episodes annually. In complex aphthosis, there are a few or many slowly healing intensely painful ulcers on the oral and perhaps genital mucosa. The latter may also be perigenital, affecting the scrotum, vulva, anus, perineum and inguinal region. Complex aphthosis features include frequently appearing ulcers with either short lesion-free periods or even repeatedly recurrent ulcers, severe pain and even systemic effects such as interference with eating and the resultant problems of inadequate nutrition. A genomewide association study, consisting of 461,106 participants reported heritability of RAS at $8.2 \%$ [5]. Moreover, a role of $T$ cell regulation in the aetiology of mouth ulcers has been reported by the study. 
Table 1

\begin{tabular}{|c|c|}
\hline Recurrent Aphthous Stomatitis (RAS) & Idiopathic \\
\hline $\begin{array}{c}\text { Drug induced } \\
\text { - } \quad \text { associated with antibiotics } \\
\text { (sulfonamides), chemotherapy drugs } \\
\text { (methotrexate), antiepileptics (barbiturates, } \\
\text { carbamazepine), diuretics, anti-inflammatories } \\
\text { (NSAIDs), and antiretrovirals, etc. } \\
\text { typically appear within one to two } \\
\text { weeks of a first exposure of a drug, and within } 1 \\
\text { to } 2 \text { days of repeat exposure }\end{array}$ & $\begin{array}{l}\text { Bullous dermatoses (erythema multiforme and its variants, } \\
\text { including Stevens-Johnson syndrome and toxic epidermal } \\
\text { necrolysis; bullous autoimmune disorders: pemphigus vulgaris, } \\
\text { cicatricial pemphigoid, epidermolysis bullosa acquisita, linear } \\
\text { IgA dermatosis; Lichen planus), pemphigus }\end{array}$ \\
\hline Autoimmune diseases & $\begin{array}{c}\text { Crohn's disease } \\
\text { Ulcerative colitis } \\
\text { Celiac disease } \\
\text { Reiter's syndrome } \\
\text { Systemic lupus erythematodes } \\
\text { Behcet's syndrome } \\
\text { Granulomatosis with polyangiitis }\end{array}$ \\
\hline Trauma & $\begin{array}{l}\text { Dental prosthesis } \\
\text { Orthodontic appliances } \\
\text { Morbus Riga Frede }\end{array}$ \\
\hline Hematologic conditions & $\begin{array}{c}\text { Anemia } \\
\text { Cyclic neutropenia } \\
\text { Hypereosinophilic syndrome }\end{array}$ \\
\hline Periodic fevers & $\begin{array}{c}\text { PFAPA (periodic fevers with aphthous stomatitis, pharyngitis, } \\
\text { and adenitis) syndrome } \\
\text { Familial Mediterranean fever (FMF) } \\
\text { Hyper IgD syndrome (HIDS) }\end{array}$ \\
\hline Nutritional deficiency & $\begin{array}{c}\text { Iron } \\
\text { Folic acid } \\
\text { Zinc } \\
\text { Vitamin B1, B2, B6, B12 } \\
\text { coxsackie A enterovirus HSV HZV CMV EBV HIV }\end{array}$ \\
\hline Bacteria & $\begin{array}{c}\text { coxsackie A, enterovirus, HSV, HZV, CIVIV, EBV, HIV } \\
\text { Tuberculosis, Syphilis }\end{array}$ \\
\hline Fungal infection & $\begin{array}{l}\text { Coccidioides immitis, Cryptococcus neoformans, Blastomyces } \\
\text { dermatidis }\end{array}$ \\
\hline Congenital disorders & $\begin{array}{l}\text { Epidermolysis bullosa } \\
\text { Chronic granulomatous disease } \\
\text { Immunodeficiency disorders }\end{array}$ \\
\hline Others & $\begin{array}{c}\text { Mouth and genital ulcers with inflamed cartilage (MAGIC) } \\
\text { syndrome } \\
\text { Sarcoidosis } \\
\text { Malignancy } \\
\text { Hormonal disturbances } \\
\text { Stress } \\
\text { Bednar's aphthae }\end{array}$ \\
\hline
\end{tabular}

Citation: Ganeva M*, Stefanov St, Lisichki K. Differential Diagnosis of Aphthous Lesions in Children .Op Acc J Bio Sci \& Res 6(3)-2020. 
The reason for complex aphthosis in $9.3 \%$ of the patients is Behcet's syndrome, a disease first reported in 1937 by the Turkish dermatologist Hulusi Behcet [6] who described relapsing oral aphthae, genital ulcers and uveitis together as symptoms of a single clinical entity. It was subsequently found to be a multisystem disease, with vascular, joint, gastrointestinal, neurological, pulmonary and cardiac involvement. Nowadays it is well known that Behcet's syndrome is associated with HLA-B51 and polymorphic variants in IL-10 and IL-23R/IL-12RB2 genes $[7,8]$ HLA-B51 frequency among inhabitants along the Silk Route population ranges $20-25 \%$ in the general population and $50-80 \%$ among BD patients. On the contrary, HLA-B51 frequency is approximately $2-8 \%$ in Northern Europe and the USA in the general population and $15 \%$ among BD patients. Interestingly, the risk of developing Behcet disease is lower among Turkish emigrants living in Germany than Turks living in Turkey. Therefore, there are other enviornmental factors

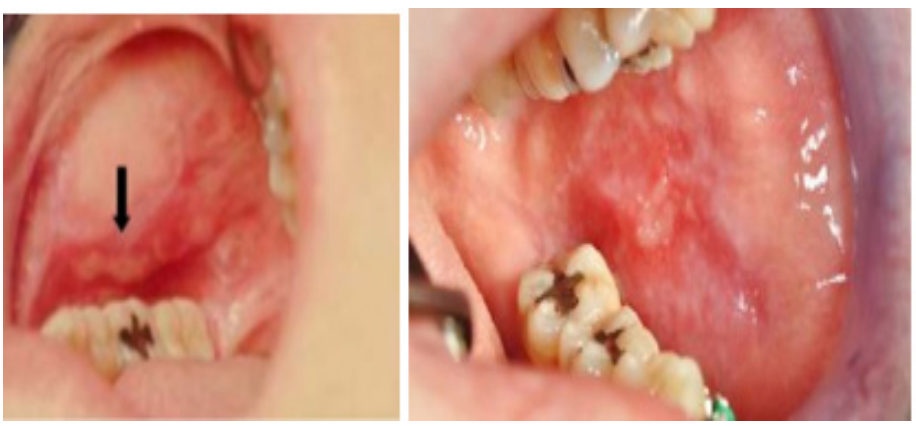

Figure 4
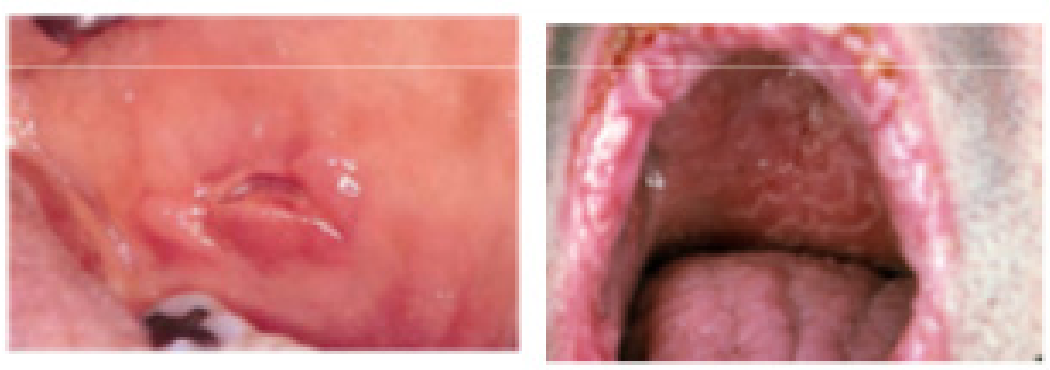

Figure 5

PFAPA (periodic fevers with aphthous stomatitis, pharyngitis, and adenitis) is established on the basis of clinical criteria that require the presence of a recurrent fever of early onset ( $<5$ years) with a clockwork periodicity (usual interval $<4$ weeks) and $\geq 1$ of the 3 associated symptoms (aphthosis, cervical adenitis, and pharyngitis), in the absence of upper respiratory tract infections and cyclic neutropenia.

Among the patients with RAS the frequency of celiac disease is between 4 and 40 percent. It should be acknowledged that oral lesions associated with celiac
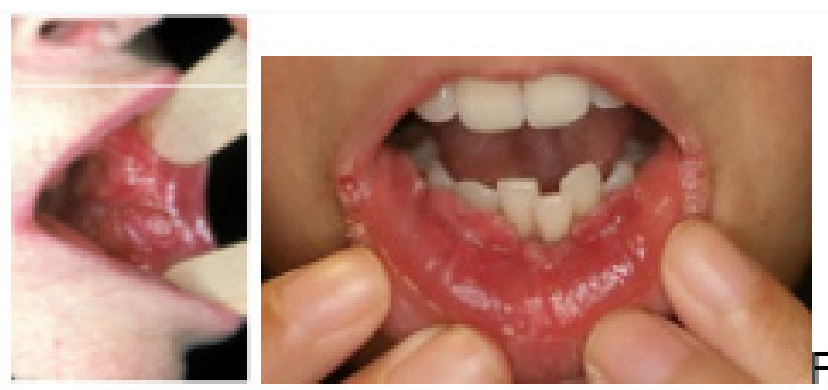

besides genetics that are important for the development of the disease. In 1990 the German Registry for AdamantiadesBehçet Disease was founded. According to it Behcet's disease starts in $14.2 \%$ of the patients during childhood [9] Oral aphthae (98.5\%), genital ulcers (64.7\%), cutaneous manifestations (73.4\%), ocular manifestations (51.6\%), and arthropathies are the most frequent clinical manifestations in Germany.

Up to twenty percent of the patients with systemic lupus erythematosus (SLE) are being diagnosed in childhood. $20-40 \%$ of the children present with aphthous lesions [10]. Aphthous lesions are the second most common mucocutaneous manifestation, after the butterfly rash. They are usually found when the disease is active. Oral ulcers are commonly found in juvenile SLE patients, and the typical lesion is a painless palatal erythematous ulcer at masticatory or keratinized mucosa, especially the hard palate. However, most ulcers including oral discoid lesions and aphthous ulcers in juvenile SLE patients appear at the lining tissue of the oral cavity (e.g., nonkeratinized epithelium covering buccal mucosa, labial mucosa, alveolar mucosa, soft palate, ventral tongue and the floor of the mouth) and sometimes are unnoticed. Oral discoid lesion is a well-defined, atrophic plaque with white radiating keratotic striae and telangiectasia at lining mucosa, especially buccal mucosa and the soft palate [11] (Figure 4).

In 1987, Marshall et al. described a new periodic fever which is now known as PFAPA syndrome [12] The diagnosis of

disease may precede gastrointestinal symptoms by several years, so screening for tissue transglutaminase and endomysial antibodies should be performed even in the absence of gastrointestinal lesions.

In cases of Crohn's disease the oral symptoms constitute up to one half of the symptoms in children [13]. The observed changes might be specific (perioral erythema, facial edema, facial ulcers, swelling or fissures of the lips, cobblestoning, linear ulcers, gingivitis, papules, nodules, mucosal polyps, granulomatous cheilitis, pyostomatitis 
vegetans, (Figure 5) and nonspecific [14] Most commonly the lesions are observed in the lips, followed by the buccal mucosal and the gingiva.

Currently, the management of RAS is aimed at supportive care. No pharmacological treatment has been curative, although several modalities have been effective in decreasing pain and erythema and increasing the rate of reepithelialization associated with healing lesions. In general one should avoid hard, acidic and salty substances such as fruit juices, citrus fruits, tomatoes, and spices like pepper, paprika and curry, as well as alcoholic and carbonated beverages. Avoiding dental care products with sodium lauryl sulfate is also desirable.

Drugs that can be used to treat oral aphthous ulcers are corticosteroids, topical antiseptic/anti-inflammatory agents, and local anesthetics. Antiseptic agents and local anesthetics should be tried first; if these are ineffective, topical corticosteroids should be used. In severe cases, local measures can be combined with systemic drugs, e.g., colchicine, pentoxifylline, or prednisolone.

In cases of Behçet's disease colchicine should be the first choice [15] Shortterm corticosteroids in combination with other drugs such as colchicine can be used as an alternative in the treatment of acute attacks. Dapsone can also be used at this stage as an effective compound. Patients with severe mucocutaneous disease or those who are unresponsive to the respected treatments can be treated with azathioprine. Cyclosporine and anti-TNF are other alternatives to control the disease in unresponsive cases. A current review of the Cochrane Collaboration analyzed 25 studies (22 of which were placebo- controlled) on systemic therapy (Prednisolone, Colchicine, Azathioprine, Cyclosporine) of oral aphthous ulcers and found no convincing evidence of efficacy [16].

\section{References}

1. Femiano F, Lanza A, Buonaiuto C, Gombos F, Nunziata M, et al. (2007) Guidelines for diagnosis and management of aphthous stomatitis. Pediatr Infect Dis J 26(8): 728-732.
2. Shulman JD (2005) Prevalence of oral mucosal lesions in children and youths in the USA. Int J Paediatr Dent 15(2): 89-97.

3. Montgomery-Cranny JA, Wallace A, Rogers HJ, Hughes SC, Hegarty AM, et al. (2015) Management of Recurrent Aphthous Stomatitis in Children. Dent Update 42(6): 564546, 569-572.

4. Kleinman DV, Swango PA, Pindborg JJ (1994) Epidemiology of oral mucosal lesions in United States schoolchildren: 1986-87. Community Dent Oral Epidemiol 22(4): 243-253.

5. Dudding,T, Haworth S, Lind PA (2019) Genome wide analysis for mouth ulcers identifies associations at immune regulatory loci. Nat Commun 10: 1052.

6. Behçet H (1937) Über rezidivierende, aphtöse, durch ein Virus verursachte Geschwüre am Mund, am Auge und an den Genitalien. Dermatologische Wochenschrift, Hamburg 105(36): 1152-1163.

7. Rogers RS (2003) Advances in experimental medicine and biology 528: 311-316.

8. Azizlerli (2003) Int J Dermatol 42: 803-806.

9. Altenburg A, Mahr A, Maldini C (2012) Epidemiologie und Klinik des Morbus Adamantiades-Behçet in Deutschland. Ophthalmologe 109: 531-541.

10. Rodsaward P, Prueksrisakul T, Deekajorndech T (2017) Oral Ulcers in Juvenile-Onset Systemic Lupus Erythematosus: A Review of the Literature. Am J Clin Dermatol 18: 755-762.

11. Rodsaward P, Prueksrisakul T, Deekajorndech T, Edwards SW, Beresford MW, et al. (2017) Oral Ulcers in JuvenileOnset Systemic Lupus Erythematosus: A Review of the Literature. Am J Clin Dermatol 18(6): 755-762.

12. Marshall GS, Edwards KM, Butler J, Lawton AR (1987) Syndrome of periodic fever, pharyngitis, and aphthous stomatitis. J Pediatr 110: 43-46.

13. Pittock S, Drumm B, Fleming P, McDermott M, Imrie C, et al. (2001) The oral cavity in Crohn's disease. J Pediatr 138(5): 767-771.

14. Katsanos K (2015) Aliment Pharmacol Ther 42: 40-60.

15. Alpsoy E (2016) Behçet's disease: A comprehensive review with a focus on epidemiology, etiology and clinical features, and management of mucocutaneous lesions. The Journal of Dermatology 43(6): 620-632.

16. Brocklehurst P, Tickle M, Glenny AM, Lewis MA, Pemberton MN, et al. (2012) Systemic interventions for recurrent aphthous stomatitis (mouth ulcers). Cochrane Database Syst Rev (9): CD005411.

\section{*Corresponding author: Margarita Ganeva, Email: magiganeva@yahoo.com}

Next Submission with BGSR follows:

- Rapid Peer Review

- Reprints for Original Copy

- E-Prints Availability

- Below URL for auxiliary Submission Link: https://biogenericpublishers.com/submit-manuscript/ 